\title{
Characteristics of Imported Malaria and Species of Plasmodium Involved in Shandong Province, China (2012-2014)
}

\author{
Chao Xu, Qing-Kuan Wei, Jin Li, Ting Xiao, Kun Yin, Chang-Lei Zhao, Yong-Bin Wang, Xiang-Li Kong, \\ Gui-Hua Zhao, Hui Sun, Xin Liu, Bing-Cheng Huang* \\ Shandong Academy of Medical Sciences, Shandong Institute of Parasitic Diseases, Shandong Provincial Reference Laboratory for Malaria \\ Diagnosis, Jining, Shandong Province 272033, People's Republic of China
}

\begin{abstract}
Malaria remains a serious public health problem in Shandong Province, China; therefore, it is important to explore the characteristics of the current malaria prevalence situation in the province. In this study, data of malaria cases reported in Shandong during 2012-2014 were analyzed, and Plasmodium species were confirmed by smear microscopy and nested-PCR. A total of 374 malaria cases were reported, $80.8 \%$ of which were reported from 6 prefectures. Of all cases, P. falciparum was dominant (81.3\%), followed by P. vivax (11.8\%); P. ovale and P. malariae together accounted for $6.4 \%$ of cases. Notably, for the first time since 2012, no indigenous case had been reported in Shandong Province, a situation that continued through 2014. Total $95.2 \%$ of cases were imported from Africa. The ratio of male/female was 92.5:1, and $96.8 \%$ of cases occurred in people $20-54$ years of age. Farmers or laborers represented $77.5 \%$ of cases. No significant trends of monthly pattern were found in the reported cases. All patients were in good condition after treatment, except for 3 who died. These results indicate that imported malaria has increased significantly since 2012 in Shandong Province, especially for $P$. falciparum, and there is an emergence of species diversity.
\end{abstract}

Key words: Plasmodium falciparum, Plasmodium vivax, Plasmodium malariae, Plasmodium ovale, imported malaria, microscopy, nested-PCR, China

\section{INTRODUCTION}

Malaria, one of the most important parasitic diseases, is widely endemic in tropical, subtropical, and temperate regions [1]. There are more than 100 malaria-endemic countries worldwide, with 216 million clinical cases globally in 2010 [2]. According to the World Malaria Report 2013, malaria caused approximately 627,000 deaths in 2012, 482,000 of which were in children under 5 years of age [3]. Malaria has a wide geographical distribution in China, where Plasmodium vivax and Plasmodium falciparum have historically had a high frequency [4]. Although clear successes in malaria control have been achieved in China during the past decades, the disease remains a serious public health problem in some regions of the country [5].

Shandong Province, across the sea with South Korea, is an

\footnotetext{
- Received 16 December 2015, revised 19 May 2016, accepted 24 May 2016.

*Corresponding author (hbc863@hotmail.com)

() 2016, Korean Society for Parasitology and Tropical Medicine

This is an Open Access article distributed under the terms of the Creative Commons Attribution Non-Commercial License (http://creativecommons.org/licenses/by-nc/4.0) which permits unrestricted non-commercial use, distribution, and reproduction in any medium, provided the original work is properly cited.
}

important coastal region of East China, and has a total area of 156,000 square kilometers (about 60,235 square miles) and a total population of 95.8 million. Historically, Shandong Province has been one of the most severely malaria-endemic areas with widespread $P$. vivax transmission via its primary vector Anopheles sinensis. Two big malaria outbreaks occurred in the province during the 1960s and 1970s, with more than 6 million and 4 million annual cases, respectively [6]. After decades of malaria prevention and control efforts, Shandong took the lead in maintaining the standard of malaria elimination established by the Ministry of Health of the People's Republic of China in 1988 [6]. Since improving prevention and monitoring activities, malaria incidence in the province had dropped to low levels and remained under 1/100,000 annually. Today, the number of local malaria cases has decreased, with frequent trade and exchange between countries, increased export of labor services, and floating populations [7]. Nevertheless, the number of cases imported from other countries has steadily increased, and P. falciparum has become the dominant species, which presents a major challenge to public health [8].

In this study, epidemiological information of malaria cases 
was analyzed. The parasite species were confirmed by microscopy and molecular assays. The study aimed to provide insight into the characteristics of malaria prevalence in Shandong Province, China during 2012-2014, to assist in the development of more effective future malaria surveillance and prevention programs.

\section{MATERIALS AND METHODS}

\section{Data and sample collection}

From 2012 to 2014, new symptomatic cases of suspected malaria infection, detected by local Centers for Disease Control and Prevention (CDCs) or medical institutions, were immediately reported to Shandong Provincial Reference Laboratory for Malaria Diagnosis. Personal information of all individuals was recorded, including sex, age, location, and treatment. A 2-ml peripheral blood sample was collected from each individual using a disposable syringe, with $0.2 \mathrm{ml}$ reserved for preparing blood smears and $1.8 \mathrm{ml}$ dropped onto filter paper for molecular testing and specimen storage. In addition, teaching demonstration blood films were used as positive control samples, and $1 \mathrm{ml}$ of peripheral blood from a healthy volunteer was collected for use as the negative control in molecular assays. The study protocol was reviewed and approved by the Ethics Committee of Shandong Institute of Parasitic Diseases. All participants were provided with informed consent forms with detailed explanation of data acquisition, sample collection, and the research purpose.

\section{Microscopic examinations}

The initial examination of blood samples for malaria parasites was performed by local hospital and CDC staff, using microscopy or rapid diagnostic tests. Then, a review microscopy trial was conducted by staff from Shandong Provincial Reference Laboratory for Malaria Diagnosis. Giemsa-stained thick and thin blood smears were made following World Health Organization recommendations $[9,10]$.

\section{Molecular assays}

Approximately $0.2 \mathrm{ml}$ blood was spotted onto a piece of Whatman $3 \mathrm{M}$ filter paper with 10-12 mm diameter. After air drying, blood specimens on the filter papers were marked with serial numbers, names, dates, and stored at $-80^{\circ} \mathrm{C}$. Malarial parasite genomic DNA was extracted using a QIAamp DNA mini kit (Qiagen, Valencia, California, USA) according to the manufacturer's instructions, and stored at $-20^{\circ} \mathrm{C}$ until use. Nested PCR was performed to amplify DNA fragments of 4 Plasmodium species (P. falciparum, P. vivax, P. malariae, and P. ovale) using specific oligonucleotide primers that target the small subunit ribosomal RNA ( $18 \mathrm{~S} \mathrm{rRNA}$ ) genes in malaria parasites, as described previously [11,12]. PCR amplicons were analyzed using $2 \%$ agarose gel electrophoresis stained with ethidium bromide and visualized under an ultraviolet transilluminator (ChemiDox XRS+ system; Bio-Rad, Hercules, California, USA). Sequencing reactions were carried out using a BigDye Terminator v3.1 Cycle Sequencing kit and ABI PRISM 3730xl DNA Analyzer (Applied Biosystems, Waltham, Massachusetts, USA), as specified in the manufacturer's protocol. Nucleotide sequences were aligned and compared using NCBI BLAST with the published sequences (GenBank accession nos. KC906718, JQ627157, KJ934253, and KC633226 for P. falciparum, P. vivax, P. malariae, and $P$. ovale, respectively). PCR products matched to known bacterial sequences with $\geq 97 \%$ identity.

\section{Plasmodium species confirmation}

A final identification of Plasmodium species was confirmed by the combined results of microscopic examinations and molecular assays. If non-concordant, the related specimens were sent to the National Malaria Diagnosis Reference Laboratory of the People's Republic of China for further confirmation.

\section{Data analysis}

Data were analyzed using Microsoft Excel 2007. Characteristics of cases were described on the basis of Plasmodium species, infection sources, population distribution (age, sex, and occupation), temporal distribution, and disease treatment.

\section{RESULTS}

\section{Overall epidemiologic profile}

A total of 374 malaria cases were identified in Shandong Province from 2012 to 2014. Of these, 93 cases occurred in 2012, 131 cases in 2013, and 150 cases in 2014; annual incidence was $0.01 / 100,000,0.14 / 100,000$, and 0.20/100,000 in local population, respectively. Case numbers increased 61.3\% by 2014 compared with 2012, with a marked increase of 40.9\% in 2013.

\section{Reporting area}

Malaria cases reported in the 17 prefectures of Shandong 


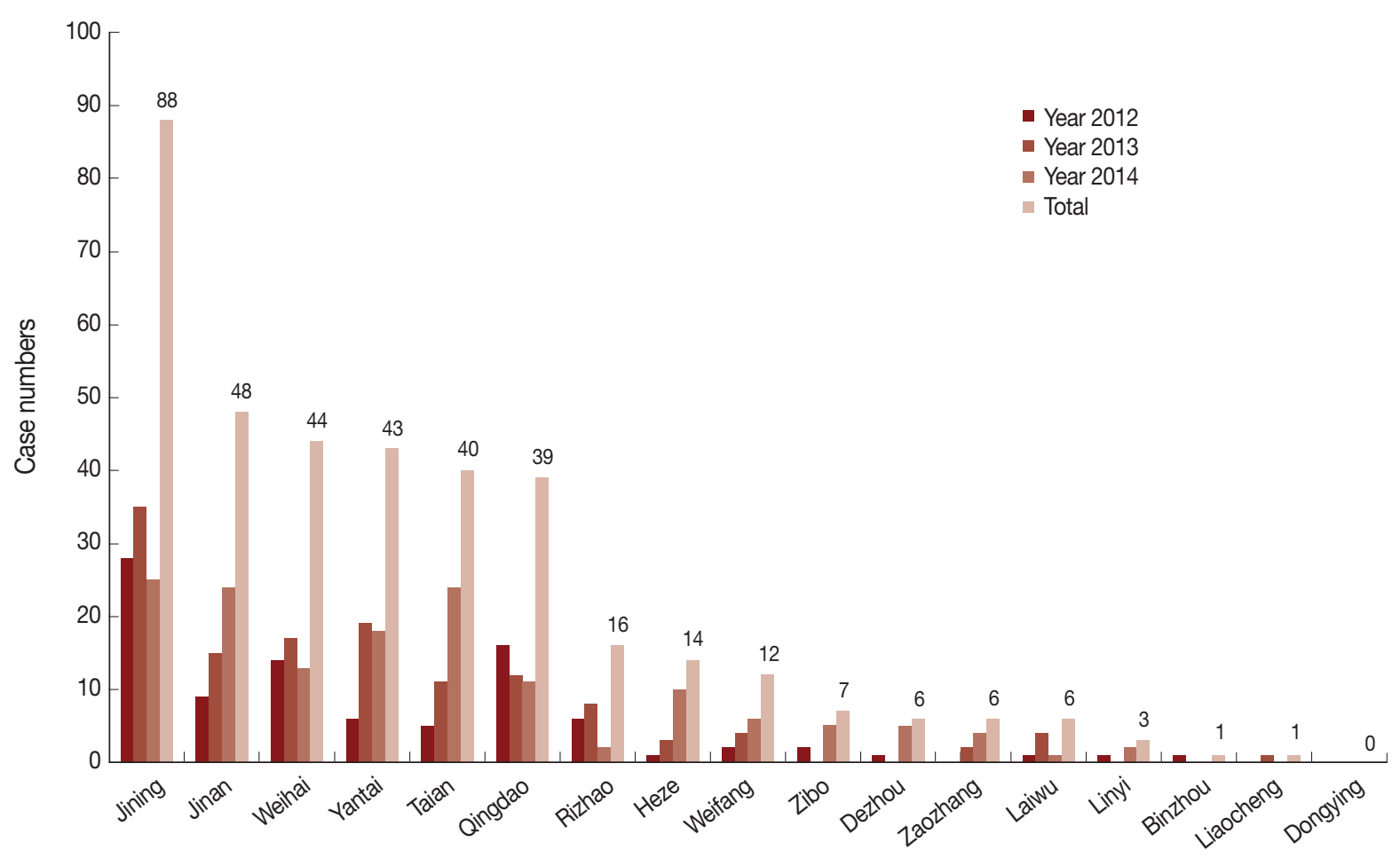

Fig. 1. Malaria case numbers reported from 17 prefectures in Shandong Province, 2012-2014. Horizontal line shows the name of 17 prefectures in Shandong and vertical line shows case numbers. Different colors of columns show the change trend of case numbers in the year 2012, 2013, 2014, and total, respectively.

Table 1. Malaria by different Plasmodium species in Shandong Province from 2012 to 2014

\begin{tabular}{lccccccc}
\hline \multirow{2}{*}{ Year } & \multicolumn{5}{c}{ No. of cases and species of Plasmodium } & \multirow{2}{*}{ Total } \\
\cline { 2 - 6 } & P. falciparum & P. vivax & P. ovale & P. malariae & Unclassified & Mixed infection \\
\hline 2012 & 67 & 21 & 3 & 0 & 2 & 0 & 93 \\
2013 & 116 & 7 & 4 & 4 & 0 & 0 & 131 \\
2014 & 121 & 16 & 9 & 4 & 0 & 0 & 150 \\
Total & $304(81.28 \%)$ & $44(11.76 \%)$ & $16(4.28 \%)$ & $8(2.14 \%)$ & $2(0.54 \%)$ & $0(0.00 \%)$ & 374 \\
\hline
\end{tabular}

Province are shown in Fig. 1. All prefectures reported cases during 2012-1014, except Dongying. Malaria cases were concentrated in the following 6 prefectures: Jining, Jinan, Weihai, Yantai, Taian, and Qingdao, together accounting for 80.8\% (302/ 374 ) of the total cases. In particular, $23.5 \%$ (88/374) of cases were reported in Jining Prefecture, which had the highest annual case numbers of all prefectures with 28 cases in 2012, 35 cases in 2013, and 25 cases in 2014.

\section{Plasmodium species composition}

According to the final confirmation of malaria species in our study, the correct rate of microscopic examinations was $96.3 \%$ (360/374). The errors, including 2 P. ovale cases, were misdiagnosed as $P$. vivax, and 4 P. vivax and 8 P. falciparum cases were failed to observe malaria parasites under the microscope. The correct rate of molecular assays was $97.3 \%$ (364/374). The errors containing 3 P. vivax cases and 7 P. falciparum cases were unable to identify species because there were no bands after electrophoresis. The final confirmation of Plasmodium species from all reported cases during 2012-2014 are shown in Table 1. P. falciparum was the dominant malaria species, accounting for $81.3 \%(304 / 374)$ of all cases and $72.0 \%$ (67/93) of cases in 2012, 88.6\% (116/131) in 2013, and 80.7\% (121/150) in 2014. P. vivax accounted for $11.8 \%$ (44/374) of cases comprising $22.6 \%$ $(21 / 93)$ in $2012,5.3 \%(7 / 131)$ in 2013 , and $10.7 \%(16 / 150)$ in 2014. The overall proportion of P. ovale was 4.3\% (16/374); $3.2 \%(3 / 93)$ in $2012,3.1 \%(4 / 131)$ in 2013 , and $6.0 \%(9 / 150)$ in 2014. The rarest species was P. malariae with only $2.1 \%$ (8/ 


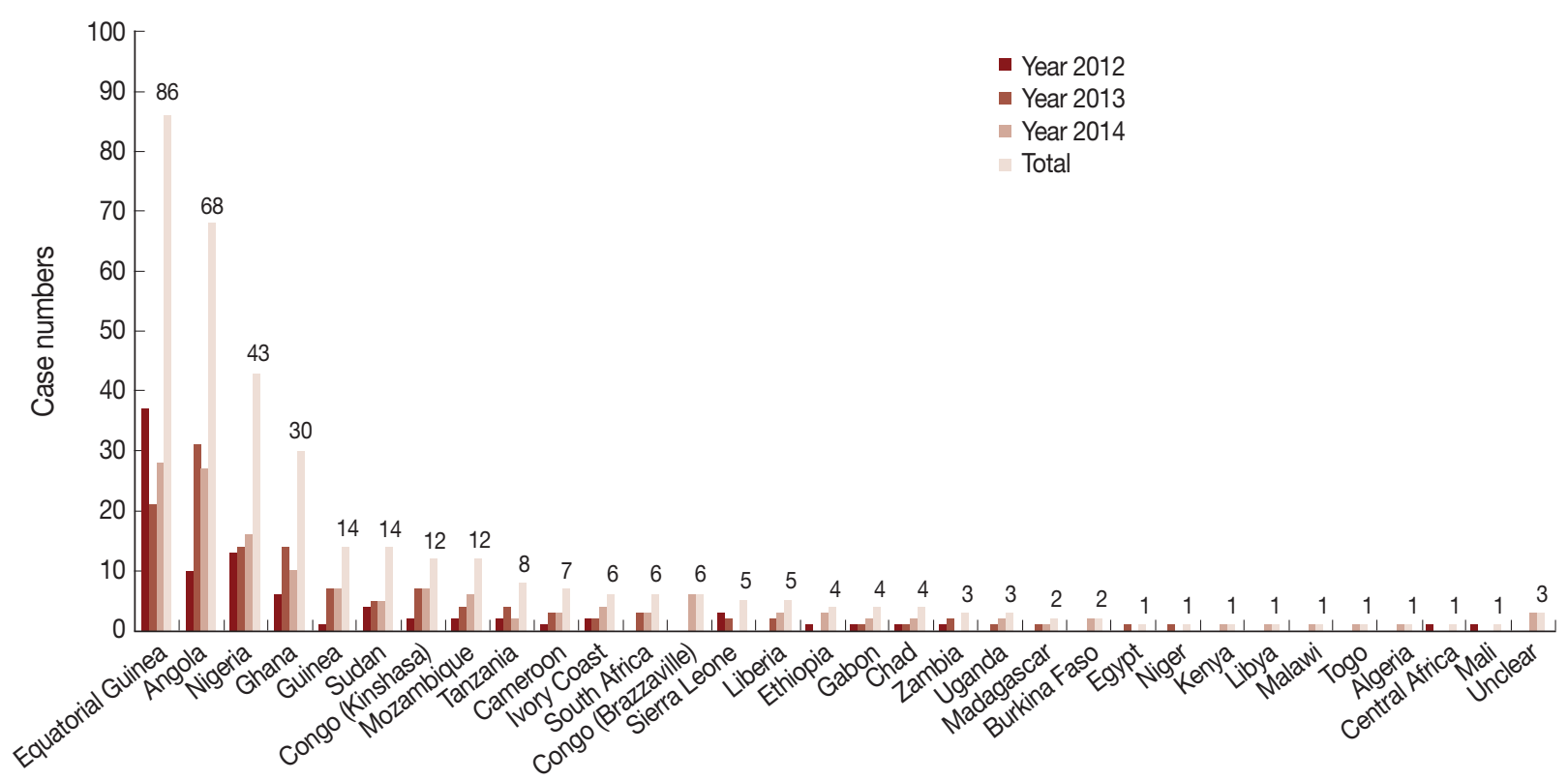

Fig. 2. Source countries of imported malaria from Africa, 2012-2014. Horizontal line shows the source countries in Africa of imported cases and vertical line shows case numbers. Different colors of columns show the change trend of case numbers in the year 2012, 2013, 2014 , and total, respectively.

$374)$ of cases including 0 in 2012, 3.1\% (4/131) in 2013, and 2.7\% (4/150) in 2014. In addition, there were 2 cases in 2012 that were unable to be classified. No mixed-infection cases were identified.

\section{Geographic distribution}

In this study, all cases were imported from other countries, in other words, no autochthonous malaria cases were reported in Shandong Province during 2012-2014. Among the cases imported from abroad, 95.2\% (356/374) were in patients who had returned from the African continent. This included 353 cases from 31 countries; however, the source country remained unidentified for 3 imported cases (Fig. 2). The 4 source countries with the most imported cases together accounted for a total $63.8 \%$ (227/356) of cases, with 24.2\% (86/356) from Equatorial Guinea, 19.1\% (68/356) from Angola, 12.1\% (43/356) from Nigeria, and 8.4\% (30/374) from Ghana. The geographical distribution of malaria imported from Africa to Shandong Province between 2012 and 2014 is shown in Fig. 3. In addition to Africa, the remaining cases were imported from 8 countries, including 6 countries in Asia (1 patient was from the China-Myanmar border area), 1 country in Oceania, and 1 in Latin America.

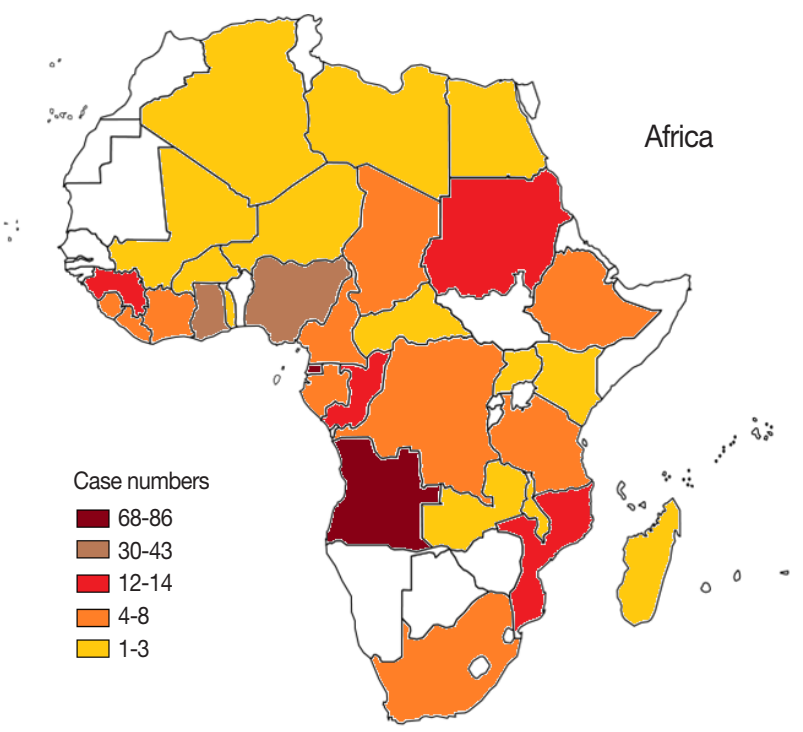

Fig. 3. Geographical distributions of imported malaria cases from Africa, 2012-2014. A blank map of Africa was quoted from www. worldatlas.com. Color difference represents the level of imported malaria from different areas in Africa.

\section{Demographic features}

The distribution of malaria cases by age is shown in Fig. 4. The oldest patient was 60 years old and the youngest was 1 year old, with the median age of 37 years. Total 96.8\% (362/374) of cases were distributed among patients from 20 to 54 years of age, with most occurring in the age group of 45-49 years 


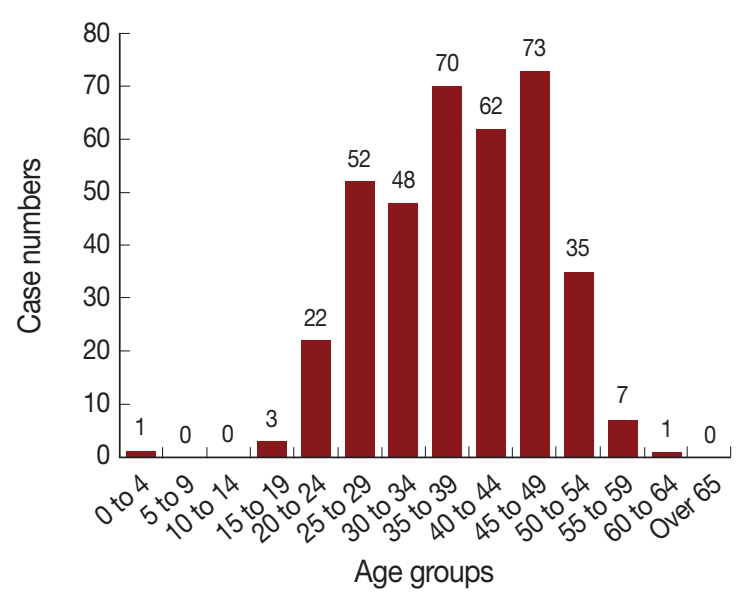

Fig. 4. Age distributions of malaria cases, 2012-2014. Horizontal line shows different age groups and vertical line shows case numbers.

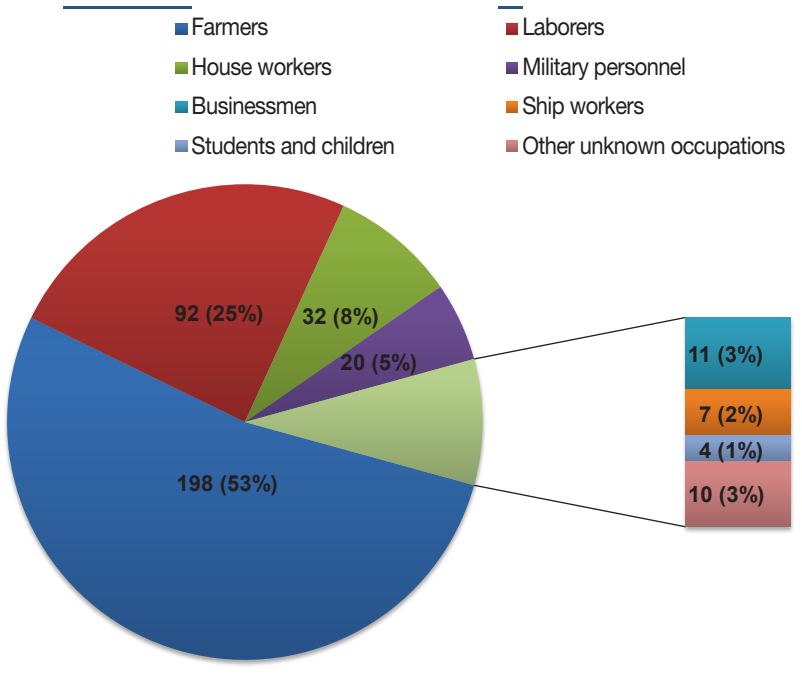

Fig. 5. Occupation distribution of malaria cases, 2012-2014. Different colored portion in the pie graph represent occupations.

$(73 / 374,19.5 \%)$. There were 370 cases in men and 4 cases in women (92.5:1). The majority of cases were among farmers $(198 / 374,52.9 \%)$ and laborers $(92 / 374,24.6 \%)$, with the remainder accounting for $22.5 \%$ of cases occurring among house workers, military personnel, businessmen, ship workers, students, children, and other unknown occupations (Fig. 5).

\section{Temporal distribution}

Monthly case reports indicated that there were no significant trends of monthly and seasonal patterns (Fig. 6). However, case numbers peaked in June for all 3 years, with a total percentage of $13.4 \%$ (50/374). Moreover, $85.0 \%$ (318/374) of patients experienced their first episode while abroad.

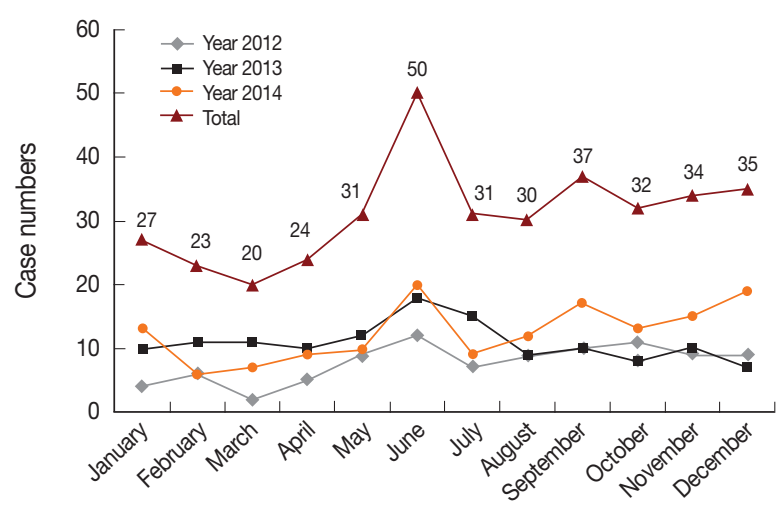

Fig. 6. Monthly distributions of reported malaria cases, 20122014. Horizontal line shows 12 months and vertical line shows case numbers. The fold line of different colors show change trend of reported numbers monthly in the year 2012, 2013, 2014, and total, respectively. The joints of lines represent case numbers in current month.

\section{Clinical treatment}

All patients with malaria in Shandong Province from 2012 to 2014 underwent accepted treatment specified according to the Technical Scheme of China Malaria Elimination (2011 edition) [13]. Uncomplicated $P$. falciparum cases received artemisinin-based combination therapies (ACTs), including dihydroartemisinin plus piperaquine or artesunate plus amodiaquine. P. vivax, P. ovale, and P. malariae cases accepted 8-day regimen of chloroquine plus primaquine. Cases of severe malaria were initially treated with artemether or artesunate injection, then peroral ACTs was used with symptomatic relief. Clinical features revealed that patients recovered well after the treatment. However, 3 migrant workers with severe $P$. falciparum returned from Ghana, Angola, and Zambia died in the year 2014. They experienced malaria episodes when coming back to China but mistook the symptom for flu and treated at home. After condition deteriorated, cases went to the hospital for treatment but the disease was too serious to be effectively rescued.

\section{DISCUSSION}

Owing to effective interventions and controls according to the National Malaria Control Programme (2006-2015) [14], no indigenous cases of malaria emerged in Shandong Province from 2012 to 2014. This situation occurred for the first time in the history of the province and has lasted for 3 years to present. Of imported cases, $80.8 \%$ were reported by local CDCs from 6 prefectures in unevenly distributed regions throughout Shandong Province. Thus, extensive health education about 
malaria should be provided in those regions from which more laborers go abroad annually.

Although malaria has decreased dramatically in recent years, the proportion of imported malaria has increased significantly and poses a threat to public health in China each year [15]. One risk of the rise in imported malaria is the spread of the parasite under conditions suitable for transmission in areas where no malaria parasites existed previously, especially in regions with high prevalence of the Anopheles vector [16]. The increase of economic aid from China to other countries is likely to have unavoidably caused laborers to migrate from abroad and peacekeeping personnel located overseas to introduce malaria domestically [17]. In this study, imported malaria has increased annually since 2012 in Shandong. Over 95\% of patients were infected in Africa, whereas those returning from Asia, Oceania, and Latin America accounted for less than 5\%, suggesting that nearly all malaria cases in the province in recent years has been transmitted from Africa. Notably, there were 3 cases reported to have been imported from Libya, Algeria, and Egypt stretch across Sahara; however, the regions had a good efficiency for controlling malaria and Anopheles mosquito's transmission. Perhaps the 3 patients were unconsciously infected in other malaria endemic regions in Africa on the way to destination or during the flight. In 2014, there was 1 case imported from the China-Myanmar border area, which is one of the most endemic malaria regions in China. This highlights the need for awareness about the potential transmission of malaria between different domestic regions as well as for imported malaria from foreign countries.

There was no evident temporal distribution of reported cases during 2012-2014. To a certain extent, this shows that trends of monthly distribution may not be directly related to the spread of mosquitoes from source countries. Malaria screening should be conducted year round, as well as continued follow-up. The main occupation of malaria patients was farmers and laborers, who generally have a lower level and quality of knowledge about the disease. Most of these patients chose to seek treatment in primary hospitals, which may have led to misdiagnosis and delayed treatment. Although 3 deaths were the result of delayed treatment, a lack of understanding of the severity of P. falciparum by primary care physicians is also an important factor.

Shandong Province was once an endemic area of China, with high prevalence of $P$. vivax and no $P$. ovale or $P$. malariae cases reported prior to 2012. However, in this study, P. falciparum ac- counted for more than $80 \%$ of all cases and had become the dominant species, whereas less than $12 \%$ of cases were infected by $P$. vivax. Furthermore, a total of 16 cases of $P$. ovale and 8 of P. malariae were detected between 2012 and 2014, all of which were identified as having been imported from Africa. These data indicate that malaria species in Shandong Province were likely to have become more diverse after a decrease in local cases and an increase of imported malaria.

Among diagnosis methods, conventional microscopy remains the most common tool and has been used in many regions of China. However, its accuracy is still significantly influenced by parasite density and equipment to microscopy [18-20]. In this study, 2 P. ovale cases were misdiagnosed as P. vivax by microscopy and were subsequently diagnosed correctly by molecular testing. The reason for this error was likely the clinical features and morphological similarities between P. ovale and P. vivax, which can be difficult to distinguish under a microscope [21].

PCR-based methods have been used since the early 1990s for the detection of Plasmodium species in humans [22]. Because sequences targeting $18 \mathrm{~S}$ rRNA gene are highly conserved and specific to malaria species, nested PCR is considered to be more sensitive and specific than microscopy, especially in cases with low parasitemia levels or mixed infections [23,24]. Moreover, distinctions between indigenous and imported strains can be made using nested PCR according to allele genotyping and homology analyses that rely on reliable molecular markers, such as circumsporozoite protein, merozoite surface protein 1, merozoite surface protein 3, glutamate-rich protein, Duffy-binding protein, and microsatellites [25-31]. Another contribution of nested PCR sequencing assays has been research on drug resistance of uncomplicated malaria, also using molecular markers such as chloroquine resistance transporter and multidrug resistance protein 1 [32-35].

Nevertheless, several factors can affect the accuracy of experimental results, for instance, the use of appropriate oligonucleotide primers, the PCR reaction system, proper storage of blood specimens, and DNA extraction methods [36]. There were some conflicting results in this study. No DNA was detected by gel electrophoresis in 10 samples where protozoan parasites were observed under the microscope; repeated experiments proved that there had an error during DNA extraction. Thus, to obtain reliable results, depending upon only 1 method cannot meet the current requirements for malaria diagnosis. Microscopy and molecular testing should be used together in a comprehensive detection system for the most accurate results. 
Shandong Provincial Reference Laboratory for Malaria Diagnosis, 1 of 19 current provincial malaria diagnosis reference laboratories in China, was established at the beginning of 2012. The laboratory is responsible for the diagnosis and review of malaria cases, establishing a library of parasite specimens, and providing professional training and technical support to ensure the most reliable testing results [37]. For effective management of imported malaria, epidemic situation management should be continued following China's 1-3-7 Strategy [38]. The local susceptibility to renewed malaria transmission should be paid attention to in view of the large number of returning workers with parasitemia and the local vector population. In addition to timely treatment, cure during the resting phase of $P$. vivax and $P$. ovale should be considered. Improved training for healthcare professionals should be conducted at local health agencies to improve staff diagnosis and treatment techniques [39]. Owing to an increase of imported cases annually in recent years, there is a need for enhanced management of floating populations, information campaigns about malaria prevention, and coordination between medical institutions and the tourism sector, service industries, and border authorities.

\section{ACKNOWLEDGMENTS}

This work was supported by Natural Science Foundation of Shandong Province (grant no. ZR2014YL036, 2012ZRC03040), and China Malaria Project of the Global Fund to Fight AIDS, Tuberculosis and Malaria (grant no. 201201055). We thank the staff of local CDCs in 17 prefectures of Shandong Province for assistance in coordinating patient information and sample collection.

\section{CONFLICT OF INTEREST}

The authors declare that they have no conflicts of interest.

\section{REFERENCES}

1. Cotter C, Sturrock HJ, Hsiang MS, Liu J, Phillips AA, Hwang J, Gueye CS, Fullman N, Gosling RD, Feachem RG. The changing epidemiology of malaria elimination: new strategies for new challenges. Lancet 2013; 382: 900-911.

2. World Health Organization. World Malaria Report, 2011. Geneva, Switzerland. World Health Organization. 2011.

3. World Health Organization. World Malaria Report, 2013. Geneva, Switzerland. World Health Organization. 2013.
4. Zhang Q, Lai S, Zheng C, Zhang H, Zhou S, Hu W, Clements AC, Zhou XN, Yang W, Hay SI, Yu H, Li Z. The epidemiology of Plasmodium vivax and Plasmodium falciparum malaria in China, 2004-2012: from intensified control to elimination. Malar J 2014; 13: 419.

5. Tang L. Progress in malaria control in China. Chin Med J (Engl) 2000; 113: 89-92.

6. Bu XQ, Wang YB, Zhao CL, Chen XX, Kong XL, Zhang BG. Effects of integrated malaria control measures in Shandong Province, 2010. Chin J Parasitol Parasit Dis 2012; 24: 116-118 (in Chinese).

7. Feng J, Xia ZG, Vong S, Yang WZ, Zhou SS, Xiao N. Preparedness for malaria resurgence in China: case study on imported cases in 2000-2012. Adv Parasitol 2014; 86: 231-265.

8. Tang LH. Diagnosis, Treatment and Management of Imported Malaria Cases. Shanghai, China. Shanghai Scientific and Technical Publishers. 2010, pp 25-29.

9. World Health Organization. Basic Malaria Microscopy. Part 1. Learner's Guide. 2nd ed. Geneva, Switzerland. WHO Press. 2010.

10. Ashraf S, Kao A, Hugo C, Christophel EM, Fatunmbi B, Luchavez J, Lilley K, Bell D. Developing standards for malaria microscopy: external competency assessment for malaria microscopists in the Asia-Pacific. Malar J 2012; 11: 352.

11. Snounou G, Viriyakosol S, Zhu XP, Jarra W, Pinheiro L, do Rosario $\mathrm{VE}$, Thaithong $\mathrm{S}$, Brown $\mathrm{KN}$. High sensitivity of detection of human malaria parasites by the use of nested polymerase chain reaction. Mol Biochem Parasitol 1993; 61: 315-320.

12. Johnston SP, Pieniazek NJ, Xayavong MV, Slemenda SB, Wilkins PP, da Silva AJ. PCR as a confirmatory technique for laboratory diagnosis of malaria. J Clin Microbiol 2006; 44: 1087-1089.

13. The Chinese Center for Disease Control and Prevention of the People's Republic of China. Technology Solutions for Eliminating Malaria (edition 2011). Available at: http://www.chinacdc. cn/tzgg/201109/t20110906_52137.htm (accessed September 06, 2011).

14. The Ministry of Health of the People's Republic of China. The National Malaria Control Programme (2006-2015). Available at: http://www.moh.gov.cn/mohbgt/pw10603/200804/27565. shtml (accessed February 22, 2006).

15. Liu Y, Hsiang MS, Zhou H, Wang W, Cao Y, Gosling RD, Cao J, Gao Q. Malaria in overseas labourers returning to China: an analysis of imported malaria in Jiangsu Province, 2001-2011. Malar J 2014; 13: 29.

16. Feng J, Yan H, Feng XY, Zhang L, Li M, Xia ZG, Xiao N. Imported malaria in China, 2012. Emerg Infect Dis 2014; 20: 1778-1780.

17. Xia ZG, Wang RB, Wang DQ, Feng J, Zheng Q, Deng CS, Abdulla S, Guan YY, Ding W, Yao JW, Qian YJ, Bosman A, Newman $\mathrm{RD}$, Ernest T, O’leary M, Xiao N. China-Africa cooperation initiatives in malaria control and elimination. Adv Parasitol 2014; 86: 319-337.

18. Makler MT, Palmer CJ, Ager AL. A review of practical techniques for the diagnosis of malaria. Ann Trop Med Parasitol 1998; 92: 419-433. 
19. Moody A. Rapid diagnostic tests for malaria parasites. Clin Microbiol Rev 2002; 15: 66-78.

20. Ohrt C, Purnomo, Sutamihardja MA, Tang D, Kain KC. Impact of microscopy error on estimates of protective efficacy in malaria-prevention trials. J Infect Dis 2002; 186: 540-546.

21. Collins WE, Jeffery GM. Plasmodium ovale: parasite and disease. Clin Microbiol Rev 2005; 18: 570-581.

22. Coleman RE, Sattabongkot J, Promstaporm S, Maneechai N, Tippayachai B, Kengluecha A, Rachapaew N, Zollner G, Miller RS, Vaughan JA, Thimasarn K, Khuntirat B. Comparison of PCR and microscopy for the detection of asymptomatic malaria in a Plasmodium falciparum/vivax endemic area in Thailand. Malar J 2006; 5: 121.

23. Snounou G, Viriyakosol S, Jarra W, Thaithong S, Brown KN. Identification of the four human malaria parasite species in field samples by the polymerase chain reaction and detection of a high prevalence of mixed infections. Mol Biochem Parasitol 1993; 58: 283-292.

24. Barker RH Jr, Banchongaksorn T, Courval JM, Suwonkerd W, Rimwungtragoon K, Wirth DF. A simple method to detect Plasmodium falciparum directly from blood samples using the polymerase chain reaction. Am J Trop Med Hyg 1992; 46: 416-426.

25. González JM, Hurtado S, Arévalo-Herrera M, Herrera S. Variants of the Plasmodium vivax circumsporozoite protein (VK210 and VK247) in Colombian isolates. Mem Inst Oswaldo Cruz 2001; 96: 709-712.

26. del Portillo HA, Longacre S, Khouri E, David PH. Primary structure of the merozoite surface antigen 1 of Plasmodium vivax reveals sequences conserved between different Plasmodium species. Proc Natl Acad Sci USA 1991; 88: 4030-4034.

27. Zakeri S, Barjesteh H, Djadid ND. Merozoite surface protein-3a is a reliable marker for population genetic analysis of Plasmodium vivax. Malar J 2006; 5: 53.

28. Xu C, Xu XL, Huang BC. Research progress on polymorphism in the merozoite surface protein-3a gene of Plasmodium vivax. Chin J Parasitol Parasit Dis 2013; 31: 473-476 (in Chinese).

29. Borre MB, Dziegiel M, Høgh B, Petersen E, Rieneck K, Riley E, Meis JF, Aikawa M, Nakamura K, Harada M. Primary structure and localization of a conserved immunogenic Plasmodium falciparum glutamate rich protein (GLURP) expressed in both the preerythrocytic and erythrocytic stages of the vertebrate life cycle.
Mol Biochem Parasitol 1991; 49: 119-131.

30. Kho WG, Chung JY, Sim EJ, Kim DW, Chung WC. Analysis of polymorphic regions of Plasmodium vivax Duffy binding protein of Korean isolates. Korean J Parasitol 2001; 39: 143-150.

31. Imwong M, Sudimack D, Pukrittayakamee S, Osorio L, Carlton JM, Day NP, White NJ, Anderson TJ. Microsatellite variation, repeat array length, and population history of Plasmodium vivax. Mol Biol Evol 2006; 23: 1016-1018.

32. Fidock DA, Nomura T, Talley AK, Cooper RA, Dzekunov SM, Ferdig MT, Ursos LM, Sidhu AB, Naudé B, Deitsch KW, Su XZ, Wootton JC, Roepe PD, Wellems TE. Mutations in the P. falciparum digestive vacuole transmembrane protein PfCRT and evidence for their role in chloroquine resistance. Mol Cell 2000; 6: 861-871.

33. Sidhu AB, Verdier-Pinard D, Fidock DA. Chloroquine resistance in Plasmodium falciparum malaria parasites conferred by pfort mutations. Science 2002; 298: 210-213.

34. Sidhu AB, Valderramos SG, Fidock DA. pfmdr1 mutations contribute to quinine resistance and enhance mefloquine and artemisinin sensitivity in Plasmodium falciparum. Mol Microbiol 2005; 57: 913-926.

35. Sanchez CP, Rotmann A, Stein WD, Lanzer M. Polymorphisms within PfMDR1 alter the substrate specificity for anti-malarial drugs in Plasmodium falciparum. Mol Microbiol 2008; 70: 786798.

36. Jelinek T, Proll S, Hess F, Kabagambe G, von Sonnenburg F, Loscher T, Kilian AH. Geographic differences in the sensitivity of a polymerase chain reaction for the detection of Plasmodium falciparum infection. Am J Trop Med Hyg 1996; 55: 647-651.

37. Yin JH, Yan H, Huang F, Li M, Xiao HH, Zhou SS, Xia ZG. Establishing a China malaria diagnosis reference laboratory network for malaria elimination. Malar J 2015; 14: 40.

38. Cao J, Sturrock HJ, Cotter C, Zhou S, Zhou H, Liu Y, Tang L, Gosling RD, Feachem RG, Gao Q. Communicating and monitoring surveillance and response activities for malaria elimination: China's "1-3-7" strategy. PLoS Med 2014; 11: e1001642.

39. The Ministry of Health of the People's Republic of China. Action Plan of China Malaria Elimination (2010-2020). Available at: http://www.moh.gov.cn/mohbgt/s10788/201005/47529.shtml (accessed May 19, 2010). 